\title{
One-Pot Fabrication and Characterization of Silver Nanoparticles Using Solanum lycopersicum: An Eco-Friendly and Potent Control Tool against Rose Aphid, Macrosiphum rosae
}

\author{
Atanu Bhattacharyya, ${ }^{1}$ Ram Prasad, ${ }^{2}$ Abdul A. Buhroo, ${ }^{3}$ \\ Prabha Duraisamy, ${ }^{4}$ Insha Yousuf, ${ }^{3}$ M. Umadevi, ${ }^{5}$ M. R. Bindhu, ${ }^{5}$ \\ Marimuthu Govindarajan, ${ }^{6}$ and Abdul L. Khanday ${ }^{3}$ \\ ${ }^{1}$ Department of Biomedical Engineering, Nanotechnology Section, Rajiv Gandhi Institute of Technology and \\ Research Centre, Cholanagar, RT Nagar Post, Hebbal, Bangalore 560032, India \\ ${ }^{2}$ Amity Institute of Microbial Technology, Amity University, Noida 201303, India \\ ${ }^{3}$ Section of Entomology, P. G. Department of Zoology, University of Kashmir, Hazratbal, Srinagar 190006, India \\ ${ }^{4}$ Department of Environmental Sciences, Bharathiar University, Coimbatore, Tamil Nadu 641046, India \\ ${ }^{5}$ Department of Physics, Mother Teresa Women's University, Kodaikanal, Tamil Nadu 624101, India \\ ${ }^{6}$ Unit of Vector Control, Phytochemistry and Nanotechnology, Department of Zoology, Annamalai University, \\ Annamalai Nagar, Tamil Nadu 608002, India
}

Correspondence should be addressed to Abdul A. Buhroo; abuhroo@yahoo.com

Received 31 March 2016; Accepted 14 September 2016

Academic Editor: Zhengjun Zhang

Copyright (c) 2016 Atanu Bhattacharyya et al. This is an open access article distributed under the Creative Commons Attribution License, which permits unrestricted use, distribution, and reproduction in any medium, provided the original work is properly cited.

\begin{abstract}
The espousal of nanotechnology is a current come-up of the present revolution. As we know that the rose aphid, Macrosiphum rosae (Hemiptera: Aphididae), is a key pest on rose plant in Kashmir Valley, India, it exhibits a worldwide distribution. In the present study, we have synthesized biologically silver nanoparticles (Ag NPs) from Solanum lycopersicum and characterized them by UV-vis spectroscopy, TEM, and X-RD analysis. The experiment was performed by leaf dip method. Insecticidal solutions of different Ag NPs concentrations, namely, 200, 300, 400, and 500 ppm, were tested on M. rosae. For assessment purposes, leaves were treated with distilled water (used as control). Aphid mortality data revealed that the Ag NPs were effective at $500 \mathrm{ppm}$ concentration. As the concentration and day's treatment increased, the aphid mortality rate also increased. There were statistically significant differences in M. rosae mortality between concentrations by LSD at 5\%. In wrapping up, the use of Ag NPs in pest control processes will be the most novel eco-friendly approach in the Kashmir Valley, India, in future.
\end{abstract}

\section{Introduction}

Rose is a prickly ornamental shrub which is the most beautiful and attractive flower in the world in Kashmir, India, often referred to as "Queen of Flowers." The genus Rosa is endemic to temperate regions of the Northern Hemisphere, including North America, Europe, Asia, and Middle East [1]. Roses are used to produce rose oil, rose water, concrete, and absolute, all of which are valuable and important base material for perfume and cosmetic industries [2]. But their main use is in cut flower industry and landscaping and they are mainly used in trade. However, rose production is significantly lowered by phytophagous insects especially aphids which are most unsafe because of their large populations and kind of damage [3]. Out of the different aphid species, Macrosiphum rosae (Linn.) is a key pest of rose, causing direct damage by sap sucking which results in discoloration of leaves, stunted growth, and gall formation, while indirect loss is incurred 
by honeydew secretion on which molds grow resulting in reduction in photosynthesis and finally the yield [4].

Application of synthetic insecticide is common practice to control insect pests in South East Asia and throughout the world. A number of effective insecticides have been reported for control of rose aphid. However, this sucking insect pest associated with rose crop has been long known to develop resistance [5]. Moreover, the uses of chemical insecticides result in secondary pest outbreak [6] besides being encountered in food products, adipose tissue, and milk of animals and have harmful effect on nontarget organisms as well [7]. The situation thus demands sustainable alternatives [8]. The use of nanoparticle pesticide is one such avenue which has potential to revolutionize modern day insect pest control [9-11].

Nanoparticles possess insecticidal efficacy due to their novel assets like extraordinary strength, chemical reactivity, and electrical conductivity. They have significant property of self-assembly, stability, specificity, encapsulation, and biocompatibility [12-14]. Thus, nanotechnology has become one of the most promising new approaches for pest control in the recent years [15]. Nanotechnology represents a new generation of environmental remediation technologies that could provide cost effective solution to some of the most challenging environmental cleanup problems [16-18]. Silver has been used in many applications in pure free metal or in compound form because it possesses antimicrobial activity against pathogens, yet it is nontoxic to human in relation to its quantity $[14,19,20]$. Although there have been numerous studies on the toxicity effects of nanoparticles on bacteria, fungi, and animal pathogens [20-25], little work has been carried out to find the lethal effects of nanoparticles on insect pest control.

Tomato (Solanum lycopersicum L.) is one of the most important vegetables worldwide because of its high consumption, year round availability, and large content of health related components. The consumption of tomatoes has been proposed to reduce the risk of several chronic diseases such as cardiovascular diseases and cancer [26, 27]. In addition, tomato consumption leads to decreased serum lipid levels and low density lipoprotein oxidation [28]. To the best of our knowledge, the biotoxicity potential of S. lycopersicum against Macrosiphum rosae is unknown. In this research paper, we report a method to biosynthesize Ag NPs using the extract of S. lycopersicum, a cheap and eco-friendly material acting as reducing and stabilizing agent. Ag NPs were characterized by UV-vis spectrophotometer, X-ray diffraction (XRD), and transmission electron microscopy (TEM). The biosynthesized Ag NPs were tested for observing their mortality effects on Macrosiphum rosae at different concentrations.

\section{Materials and Methods}

2.1. Materials. Silver nitrate $\left(\mathrm{AgNO}_{3}\right)$ was purchased from Sigma Aldrich Chemicals, India. The glassware was acidwashed thoroughly and then rinsed with Millipore Milli-Q water. Solanum lycopersicum L. was collected from local supermarket in Kodaikanal, Tamil Nadu, India.
2.2. Synthesis of Silver Nanoparticles. Synthesis of Ag NPs was carried out by the method of Umadevi et al. [29], with slight modification, where $100 \mathrm{~g}$ of washed Solanum lycopersicum was compressed by the mixer grinder for extraction. The extract was estranged by centrifugation at $1000 \mathrm{rpm}$ for $15 \mathrm{~min}$ to remove inexplicable fraction and macromolecules. Then the light yellow extract was collected for further experiments. $15 \mathrm{~mL}$ of $S$. lycopersicum extract was mixed to $50 \mathrm{~mL}$ aqueous solution of $\mathrm{AgNO}_{3}(1 \mathrm{mM})$ and stirring continued for $2 \mathrm{~min}$ at $30^{\circ} \mathrm{C}$. Reduction takes place rapidly as indicated by reddish brown color of the solution which gives silver colloid. During the synthesis, the prepared nanoparticles, initially, become colorless and turned into a characteristic reddish brown for Ag NPs; after that the prepared nanoparticles showed no further change in color, implying the completion of reaction. This stability results from a potential barrier that develops as a result of the competition between weak Van der Waals forces of attraction and electrostatic repulsion.

2.3. Characterization Studies. The bioreduction of $\mathrm{Ag}^{+}$ions was monitored using UV-vis spectrophotometer (UV-160v, Shimadzu, Japan). Analysis of size and morphology of Ag NPs was performed by transmission electron microscopy (TEM Technite 10 Philips). The purified crystalline Ag NPs were examined by XRD analysis.

2.4. Insect Culture and Bioassay. A colony of test insect, Macrosiphum rosae, was established on potted rose plants under a temperature range of $20-22 \pm 2^{\circ} \mathrm{C}$ in the Entomology Laboratory, Department of Zoology, University of Kashmir, India. Bioassay for effects of the Ag NPs on wingless (apterous), viviparous female aphids was taken into account for our experiment. The experiment was determined by dipping leaves in different concentrations $(200,300,400$, and $500 \mathrm{ppm}$ ) which were prepared by dissolving $2,3,4$, and $5 \mathrm{mgs}$ of Ag NPs in $10 \mathrm{~mL}$ of distilled water followed by addition of $0.05 \mathrm{~mL}$ ethanol to observe the more or less clear solution. Moreover, $10 \mathrm{~mL}$ of distilled water with $0.05 \mathrm{~mL}$ ethanol was taken for control experiment. The solutions were stirred continuously for about an hour with a polished blunt end of a glass rod. The nanoparticle solution turned brownish in color and was kept as such overnight, thereafter accessible for our experiment. Then we released 10 female aphids on the treated leaves. Insect mortality was counted after $24,48,72$, and 96 hours of treatment.

2.5. Statistical Analysis. Statistical analysis was performed using SPSS version 20.0 for Windows. The mortality data were analyzed using one-way ANOVA to compare effects among treatments. The results were expressed as percentage mortality $( \pm$ SE) and treatment effects were statistically significant at $P \leq 0.05$ using LSD test.

\section{Results}

The Ag NPs were synthesized from S. lycopersicum extract by maintaining the time and then $50 \mathrm{~mL}$ aqueous solution of $\mathrm{AgNO}_{3}(1 \mathrm{mM})$ and stirring continued for $2 \mathrm{~min}$ at specific 


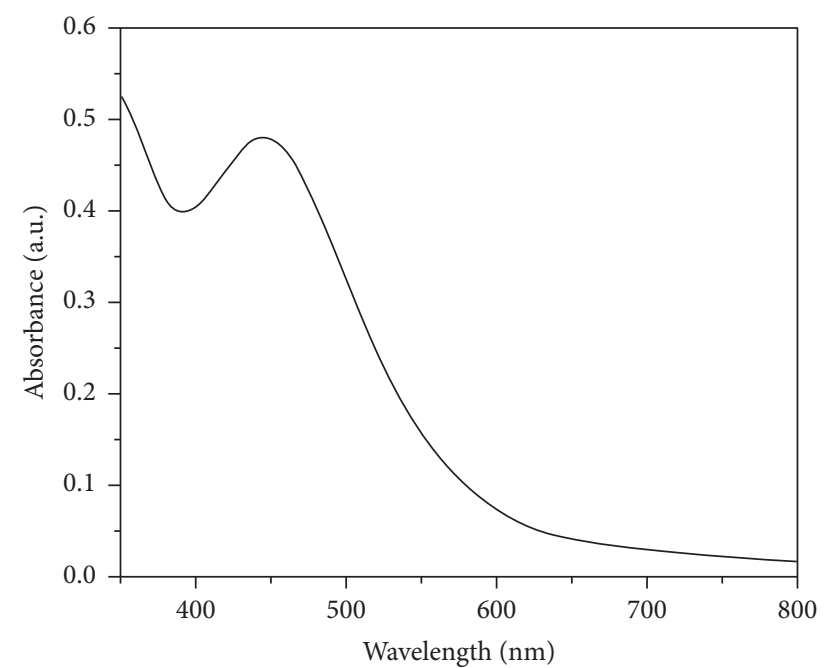

(a)

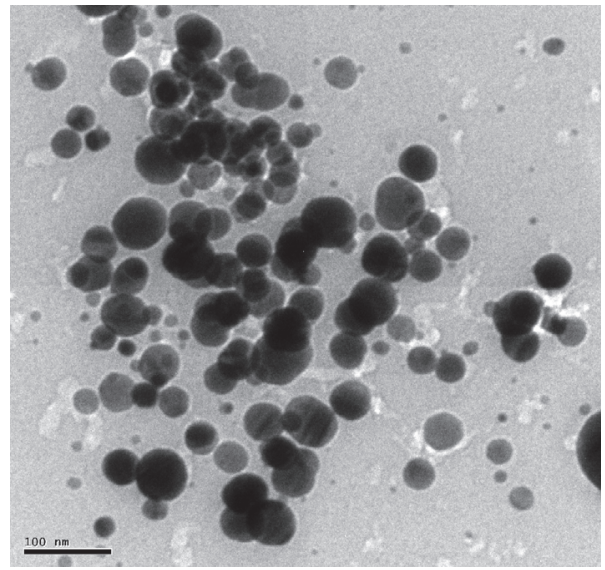

(c)

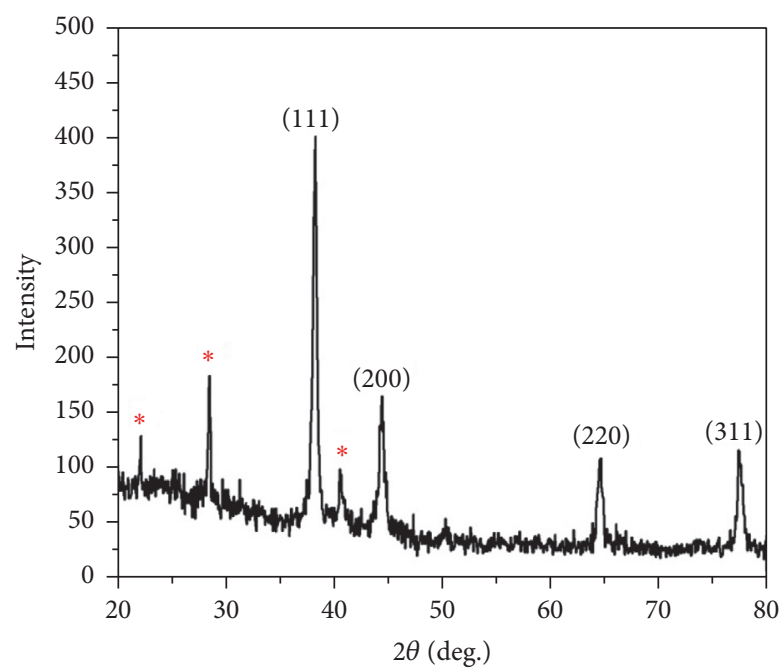

(b)

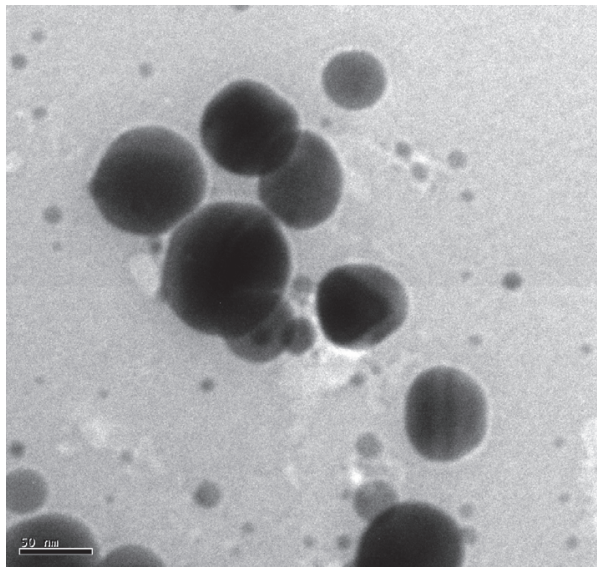

(d)

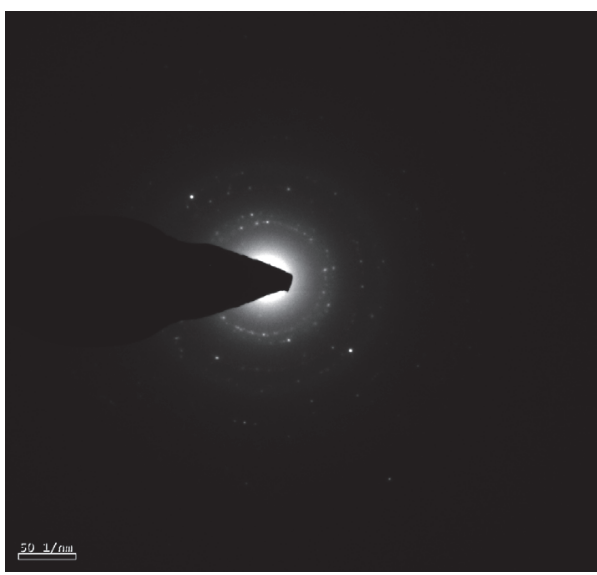

(e)

FIGURE 1: Characterization of silver nanoparticles from Solanum lycopersicum. (a) Optical absorption spectra for prepared Ag NPs. (b) X-ray diffraction pattern of prepared Ag NPs. (c) and (d) TEM micrograph of Ag NPs synthesized by using the extract of S. lycopersicum. (e) Selected area electron diffraction showing the characteristic crystal planes of elemental silver.

temperature $30^{\circ} \mathrm{C}$. The reduction process was performing extremely quickly which altered into reddish brown color for colloid formation. Furthermore, this formation is also due to the excitation of surface plasmon resonance (at $445 \mathrm{~nm}$ ) effect and therefore the reduction of $\mathrm{AgNO}_{3}$ is complete. Thus, the stable $\mathrm{AgNO}_{3}$ is shaped. Then the characterization of the nanomaterials exhibits unique optical property performed by UV-vis spectroscopy (Figure 1(a)). Moreover, 
TABLE 1: Effect of different concentrations of Ag NPs on adult female M. rosae.

\begin{tabular}{lcccc}
\hline \multirow{2}{*}{ Treatment $(\mathrm{ppm})$} & \multicolumn{4}{c}{ Percentage mortality days after treatment } \\
& 1 st & 2nd & 3rd & 4 th \\
\hline 200 & $10.0( \pm 5.78)^{\mathrm{a}}$ & $30.0( \pm 5.78)^{\mathrm{a}}$ & $50.0( \pm 5.77)^{\mathrm{a}}$ & $80.0( \pm 5.78)^{\mathrm{a}}$ \\
300 & $30.0( \pm 5.80)^{\mathrm{be}}$ & $50.0( \pm 5.88)^{\mathrm{be}}$ & $70.0( \pm 5.87)^{\mathrm{b}}$ & $90.0( \pm 5.80)^{\mathrm{ac}}$ \\
400 & $40.0( \pm 5.87)^{\mathrm{cef}}$ & $60.0( \pm 5.79)^{\mathrm{cef}}$ & $90.0( \pm 5.84)^{\mathrm{ce}}$ & $100.0( \pm 5.85)^{\mathrm{bc}}$ \\
500 & $50.0( \pm 5.88)^{\mathrm{df}}$ & $70.0( \pm 5.87)^{\mathrm{df}}$ & $100.0( \pm 5.86)^{\mathrm{de}}$ & \\
Control & 0.0 & 0.0 & 0.0 & 0.0 \\
\hline
\end{tabular}

${ }^{*}$ Mean of 3 replications/treatments; figures in the parentheses show standard error $( \pm$ SE); means followed by same letters in each column are not significantly different by LSD at $5 \%$.

the XRD pattern of the prepared Ag NPs clearly observes the diffraction peaks at $38.20^{\circ}, 44.39^{\circ}, 64.52^{\circ}$, and $77.43^{\circ}$ in the $2 \theta$ range corresponding to (111), (200), (220), and (311) reflection planes which were exactly indexed to the face centered cubic (fcc) structure of metallic silver, respectively (JCPDS 040783) (Figure $1(\mathrm{~b})$ ). The observed peaks at $22.11^{\circ}, 28.43^{\circ}$, and $40.63^{\circ}$ in $2 \theta$ range indicate the presence of ascorbic acid denoted by the "*" (JCPDS 22-1560 and 32-1637) in the $S$. lycopersicum extract. Generally, the broadening of peaks in the XRD patterns of solids is attributed to particle size effects [30]. Broader peaks signify smaller particle size and reflect the effects due to experimental conditions on the nucleation and growth of the crystal nuclei [31]. The average crystallite sizes denote the lattice constant which is calculated by "Bragg's law"; that is, $2 d \sin \theta=n$ times wavelength values. For this reason, we have taken XRD pattern of our samples to know $d$ spacing values of the said nanoparticles. The lattice parameter for the prepared silver nanoparticles works out to be $a=$ $4.0864 \AA$ which is in very high-quality concurrence in the standard data file JCPDS number 04-0783.

Therefore, TEM images of the reduced Ag NPs of $S$. lycopersicum are shown in Figures 1(c) and 1(d). It shows the formation of spherical shaped nanoparticles. The strong interaction between number of biomolecules in the tomato fruit extract and surface of nanoparticles was sufficient to the formation of spherical nanoparticles preventing them from sintering and providing size reduction of spherical nanoparticles. The presence of lattice fringes helps to produce the crystalline nature of the prepared nanomaterials. The selected area of electron diffraction pattern of S. lycopersicum is shown in the inset of Figure 1(e) which reveals that the rings could be indexed based on the fcc structure of silver which revealed the crystalline nature of the nanoparticles.

Thus, the XRD pattern for Ag NPs denotes the peaks at $38.20^{\circ}, 44.39^{\circ}, 64.52^{\circ}$, and $77.43^{\circ}$ in the $2 \theta$ range corresponding to (111), (200), (220), and (311) reflection planes which were exactly indexed to the face centered cubic (fcc) structure of metallic silver, respectively (JCPDS 040783), in the S. lycopersicum extract. The sharpening of the peaks clearly indicates that the particles are the spherical nanoparticles (confirmed by the TEM). The average size of the Ag NPs is estimated by using Debye-Scherrer's formula $D=0.9 \lambda / \beta \cos \theta$, where " $\lambda$ " represents $X$-ray wavelength $(0.1541 \mathrm{~nm})$, " $\beta$ " is the maximum intensity and " $\theta$ " is Bragg's angle.

Then the bioassay was followed for assessing the insecticidal property of Ag NPs The results showed that 200 and

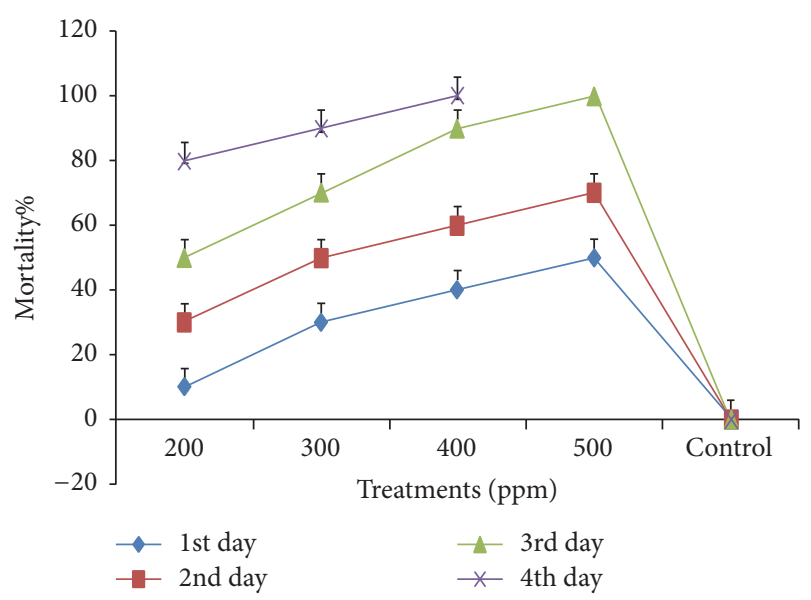

FIGURE 2: Effect of different concentrations of silver coated nanoparticles on $M$. rosae.

$300 \mathrm{ppm}$ concentrations produced the highest percentage mortality of $80 \%$ and $90 \%$, respectively, on the 4 th day after treatment (Table 1 and Figure 2). At 400 ppm concentration, mortality reached a maximum of $100 \%$ on the 4 th day after treatment. However, at $500 \mathrm{ppm}$ concentration, mortality reached a maximum of $100 \%$ only on the 3rd day after treatment. The maximum mortalities of $50 \%, 70 \%$, and $100 \%$ were obtained at $500 \mathrm{ppm}$ on the 1st, 2nd, and 3rd day, respectively, after the application of Ag NPs (Table 1). There were statistically significant differences among the treatments on each day after application of biogenic Ag NPs. On 1st, 2nd, and 3rd day 400 and $500 \mathrm{ppm}$ produced significantly higher mortalities than 200 and $300 \mathrm{ppm}$ treatment concentrations (Table 1). On the 4th day, $400 \mathrm{ppm}$ produced significantly higher mortality than $200 \mathrm{ppm}$ and $300 \mathrm{ppm}$ treatment concentrations. There was almost no mortality in the control aphids (Figure 3(a)). Moreover, one-way ANOVA on rose aphid, $M$. rosae experiment with Ag NPs, proposed the following suggestion as mortality on $24,48,72$, and $96 \mathrm{hrs;}$ $F$ and $P$ values were highly significant. Therefore, it exposes a tremendous effect of the synthesized nanomaterials on rose aphid (Table 1 and Figures 3(a)-3(f)).

The above results clearly show that all the nanoparticle treatments and mortality of adult aphid increased by increasing the dose of the nanoparticle solution. The Ag NPs should 


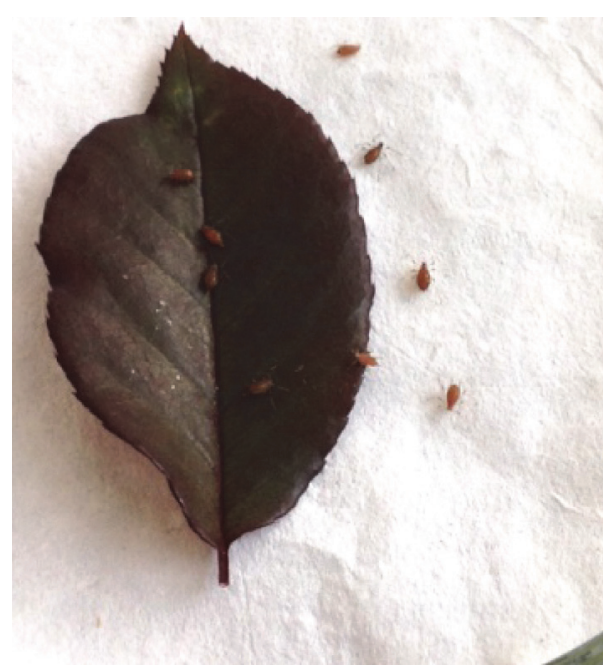

(a)

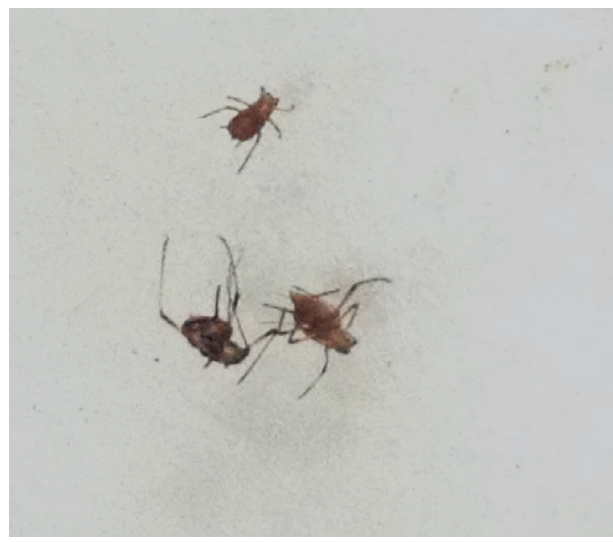

(c)

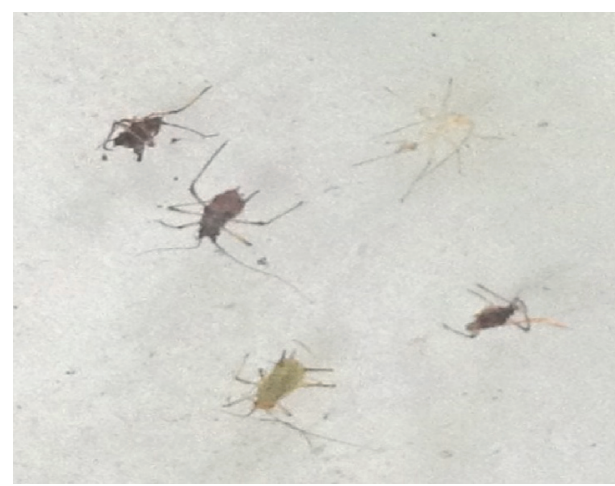

(e)

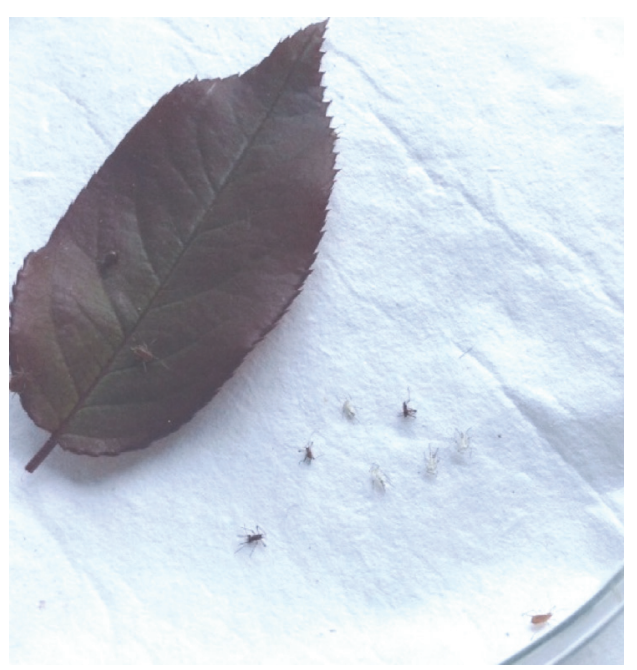

(b)

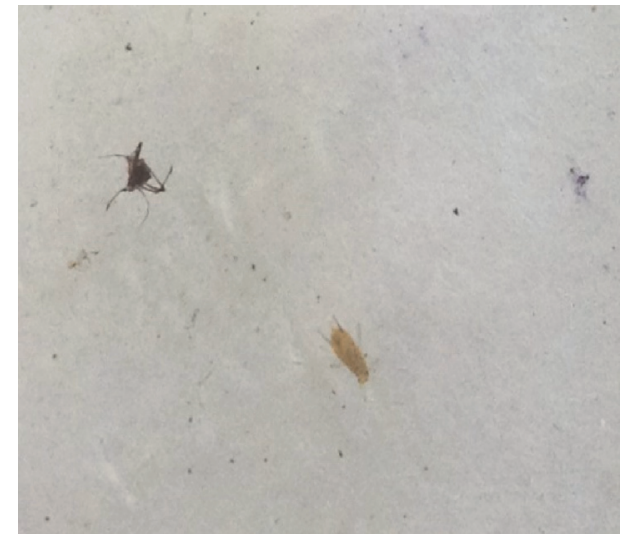

(d)

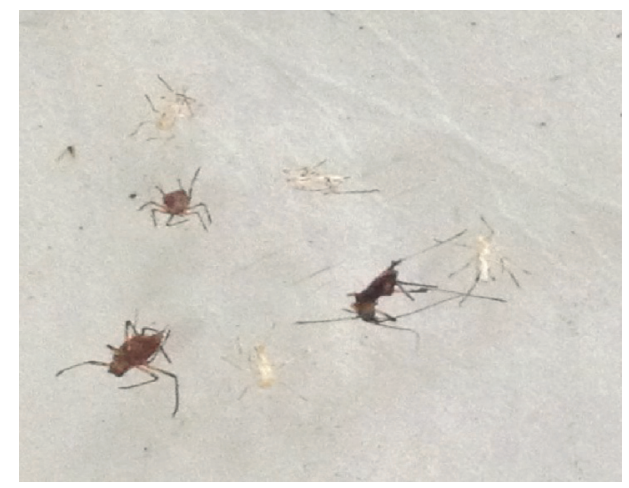

(f)

FIgure 3: Insecticidal activity. (a) Aphids in the control experiment. (b) M. rosae treated with 500 ppm concentration of Ag NPs. (c) Dead M. rosae on the 1st day after treatment of 500 ppm. (d) Dead M. rosae on 2nd day after treatment of 500 ppm. (e) Dead M. rosae on 3rd day after treatment of $500 \mathrm{ppm}$. (f) Dead M. rosae on 4th day after treatment of $500 \mathrm{ppm}$.

be tested at concentrations higher than $300 \mathrm{ppm}$ to determine the effective dose resulting in 50\% aphid mortality. In terms of time and quantity of Ag NPs required, it is, therefore, acceptable to recommend $500 \mathrm{ppm}$ concentration producing $50 \%$ aphid mortality within the shortest possible time with minimal crop damage/injury.

\section{Discussions}

Our results clearly denote that the Ag NPs of about $13 \mathrm{~nm}$ size have the capability to expose the maximum mortality in $M$. rosae (rose aphid). The experimental data also revealed that the 500 ppm has the ability to expose the maximum mortality. 
It has been reported that Ag NPs possess insecticidal properties due to changes in its morphological and structural features in relation to surface area [32,33]. The consequences of the experiment also showed that 200 and 300 ppm concentration of Ag NPs produced the higher percentage mortality of $80 \%$ and $90 \%$, respectively, on the 4 th day after treatment which indicates the initiation effect of the nanomaterials for exposition of its insecticidal property. At 400 and $500 \mathrm{ppm}$ concentration we can observe the mortality increases. It has been reported that the accumulation of silver can lead to adverse effects on growth, because of their different physicochemical properties and free ions released from $\mathrm{Ag}$ NPs $[34,35]$. Moreover, the maximum mortalities like 50\%, $70 \%$, and $100 \%$ were obtained at $500 \mathrm{ppm}$ on $1 \mathrm{st}, 2 \mathrm{nd}$, and 3 rd day of experiment, respectively, after the treatment of $\mathrm{Ag}$ NPs. The experiment, however, exposes the dose dependent mortality and there is a possibility that Ag NPs enter into the physiology of rose aphid M. rosae which leads to altering the cell physiology and thus leads to mortality. It is very pertinent to consider the reports of Huk et al. [35] that the nanoparticles encompass the ability to enter in the cells which cause cellular damage and cell death [36]. It may be due to necrosis of the said insect cell and thus leads to mortality of the alleged insect pests. Though more experiments are essential to know the actual cause of death of aphids, however, as far as our knowledge is concerned, this is the first report to control the rose aphid by Ag NPs. Therefore, this can be reflected as valuable eco-friendly tools in insect pest management programs, especially on M. rosae in Kashmir Valley.

\section{Conclusions}

We have developed a fast, eco-friendly, and convenient method for biogenic synthesis of Ag NPs from silver nitrate using Solanum lycopersicum at room temperature. Color changes from colorless to brownish due to surface plasmon resonance during the reaction with $S$. lycopersicum extract solution resulting in the formation of Ag NPs, which is confirmed by UV-vis spectroscopy. TEM micrograph has shown spherical Ag NPs of size about $13 \mathrm{~nm}$ are obtained. Further studies will be conducted to study the pest control management of the synthesized Ag NPs from S. lycopersicum.

\section{Competing Interests}

The authors declare that they have no conflict of interests.

\section{References}

[1] R. Phillips and M. Rix, Roses, vol. 224, Random House, New York, NY, USA, 1988.

[2] F. Ayci, M. Aydinli, Ö. A. Bozdemir, and M. Tutaş, "Gas chromatographic investigation of rose concrete, absolute and solid residue," Flavour and Fragrance Journal, vol. 20, no. 5, pp. 481486, 2005.

[3] B. Jaskiewicz, "The species composition and number of aphids on the shrubs of Pinus mugo turra and Rosa sp. in urban conditions," Electronic Journal of Polish Agricultural Universities, vol. 6, no. 2, p. 12, 2003.
[4] A. Z. Jalalizand, A. Karimi, M. E. Modaresi, and E. Mahamoodi, "Determing morphological traits and genetic diversity of rose aphids using RAPD and RFLP-PCR molecular markers," in Proceedings of the International Conference on Applied Life Sciences (ICALS '12), F. Nejadkoorki, Ed., p. 324, Konya, Turkey, September 2012.

[5] R. L. Metcalf, "Changing role of insecticides in crop protection," Annual Review of Entomology, vol. 25, no. 1, pp. 219-256, 1980.

[6] I. N. Oka and D. Pimentel, "Corn susceptibility to corn leaf aphids and common corn smut after herbicide treatment," Environmental Entomology, vol. 3, no. 6, pp. 911-915, 1974.

[7] K. N. Meherotra, "New trends in use of insecticides," Proc Increasing Crop Productivity, vol. 20, pp. 353-369, 1986.

[8] B. S. Parmar, "Scope of botanical pesticides in integrated pest management," Journal of Insect Science, vol. 6, pp. 15-20, 1993.

[9] A. Bhattacharyya, R. Chandrasekar, A. K. Chandrau, T. T. Epidi, and R. S. Prakasham, "Application of nanoparticles in sustainable agriculture: its current status," in Short Views on Insect Biochemistry and Molecular Biology, chapter 19, pp. 429448, International Book Mission, Academic, Manhattan, NY, USA, 1st edition, 2014.

[10] S. Singh, B. K. Singh, S. Yadav, and A. Gupta, "Applications of nanotechnology in agricultural and their role in disease management," Research Journal of Nanoscience and Nanotechnology, vol. 5, no. 1, pp. 1-5, 2015.

[11] R. Dixit, Wasiullah, D. Malaviya et al., "Bioremediation of heavy metals from soil and aquatic environment: an overview of principles and criteria of fundamental processes," Sustainability, vol. 7, no. 2, pp. 2189-2212, 2015.

[12] B. Ehdaie, "Application of nanotechnology in cancer research: review of progress in the National Cancer Institute's alliance for nanotechnology," International Journal of Biological Sciences, vol. 3, no. 2, pp. 108-110, 2007.

[13] R. Prasad, V. Kumar, and K. S. Prasad, "Nanotechnology in sustainable agriculture: present concerns and future aspects," African Journal of Biotechnology, vol. 13, pp. 705-713, 2014.

[14] R. Prasad, "Synthesis of silver nanoparticles in photosynthetic plants," Journal of Nanoparticles, vol. 2014, Article ID 963961, 8 pages, 2014.

[15] A. Bhattacharyya, A. Bhaumik, P. U. Rani, S. Mandal, and T. T. Epidi, "Nano-particles-a recent approach to insect pest control," African Journal of Biotechnology, vol. 9, no. 24, pp. 3489-3493, 2010.

[16] C. R. Chinnamuttu and P. M. Boopathi, "Nanotechnology and agroecosystem," Madras Agricultural Journal, vol. 96, pp. 17-31, 2009.

[17] R. Prasad, R. Pandey, and I. Barman, "Engineering tailored nanoparticles with microbes: quo vadis?" WIREs Nanomedicine and Nanobiotechnology, vol. 8, no. 2, pp. 316-330, 2016.

[18] N. Aziz, M. Faraz, R. Pandey et al., "Facile algae-derived route to biogenic silver nanoparticles: synthesis, antibacterial, and photocatalytic properties," Langmuir, vol. 31, no. 42, pp. 1160511612,2015

[19] S. Y. Yeo, H. J. Lee, and S. H. Jeong, "Preparation of nanocomposite fibers for permanent antibacterial effect," Journal of Materials Science, vol. 38, no. 10, pp. 2143-2147, 2003.

[20] J. L. Elchiguerra, J. L. Burt, J. R. Morones et al., "Interaction of silver nanoparticles with HIV-1," Journal of Nanobiotechnology, vol. 6, pp. 1-13, 2005.

[21] P. D. Bragg and D. J. Rainnie, "The effect of silver ions on the respiratory chain of Escherichia coli," Canadian Journal of Microbiology, vol. 20, no. 6, pp. 883-889, 1974. 
[22] Q. L. Feng, J. Wu, G. Q. Chen, F. Z. Cui, T. N. Kim, and J. O. Kim, "A mechanistic study of the antibacterial effect of silver ions on Escherichia coli and Staphylococcus aureus," Journal of Biomedical Materials Research, vol. 52, no. 4, pp. 662-668, 2000.

[23] U. Samuel and J. P. Guggenbichler, "Prevention of catheterrelated infections: the potential of a new nano-silver impregnated catheter," International Journal of Antimicrobial Agents, vol. 23, no. 1, pp. S75-S78, 2004.

[24] K. M. Reddy, K. Feris, J. Bell, D. G. Wingett, C. Hanley, and A. Punnoose, "Selective toxicity of zinc oxide nanoparticles to prokaryotic and eukaryotic system," Applied Physics Letters, vol. 90, pp. 2139021-2139023, 2007.

[25] A. G. S. Cuthbertson, "Chemical and ecological control methods for Epitrix spp," Global Journal of Environmental Science and Management, vol. 1, no. 1, pp. 95-97, 2015.

[26] P. C. H. Hollman, M. G. L. Hertog, and M. B. Katan, "Analysis and health effects of flavonoids," Food Chemistry, vol. 57, no. 1, pp. 43-46, 1996.

[27] A. V. Rao and S. Agarwal, "Role of lycopene as antioxidant carotenoid in the prevention of chronic diseases," Nutrition Research, vol. 19, no. 2, pp. 305-323, 1999.

[28] A. Agarwal, H. Shen, S. Agarwal, and A. V. Rao, "Lycopene content of tomato products: its stability, bioavailability and in vivo antioxidant properties," Journal of Medicinal Food, vol. 4, no. 1, pp. 9-15, 2001.

[29] M. Umadevi, M. R. Bindhu, and V. Sathe, "A novel synthesis of malic acid capped silver nanoparticles using Solanum lycopersicums fruit extract," Journal of Materials Science \& Technology, vol. 29, no. 4, pp. 317-322, 2013.

[30] R. Jenkins and R. L. Snyder, "Diffraction theory," in Introduction to X-Ray Powder Diffractometry, vol. 138, John Wiley \& Sons, Hoboken, NJ, USA, 1996.

[31] A. Becheri, M. Dürr, P. L. Nostro, and P. Baglioni, "Synthesis and characterization of zinc oxide nanoparticles: application to textiles as UV-absorbers," Journal of Nanoparticle Research, vol. 10, no. 4, pp. 679-689, 2008.

[32] M. Vijaya Sankar and S. Abideen, "Pesticidal effect of green synthesized silver and lead nanoparticles using Avicennia marina against grain storage pest Sitophilus oryzae," International Journal of Nanomaterials and Biostructures, vol. 5, no. 3, pp. 32-39, 2015.

[33] R. Eisler, "Silver hazards to fish, wildlife and invertebrates: a synoptic review," Biological Report 32 and Contaminant Hazard Reviews Report 32, US Department of the Interior, National Biological Service, Washington, DC, USA, 1997.

[34] F. Sambale, S. Wagner, F. Stahl, R. R. Khaydarov, T. Scheper, and D. Bahnemann, "Investigations of the toxic effect of silver nanoparticles on mammalian cell lines," Journal of Nanomaterials, vol. 2015, Article ID 136765, 9 pages, 2015.

[35] A. Huk, E. Izak-Nau, N. Yamani et al., "Impact of nanosilver on various DNA lesions and HPRT gene mutations-effects of charge and surface coating," Particle and Fibre Toxicology, vol. 12, article 25, 2015.

[36] C. Buzea, I. I. Pacheco, and K. Robbie, "Nanomaterials and nanoparticles: sources and toxicity," Biointerphases, vol. 2, no. 4, pp. MR17-MR172, 2007. 

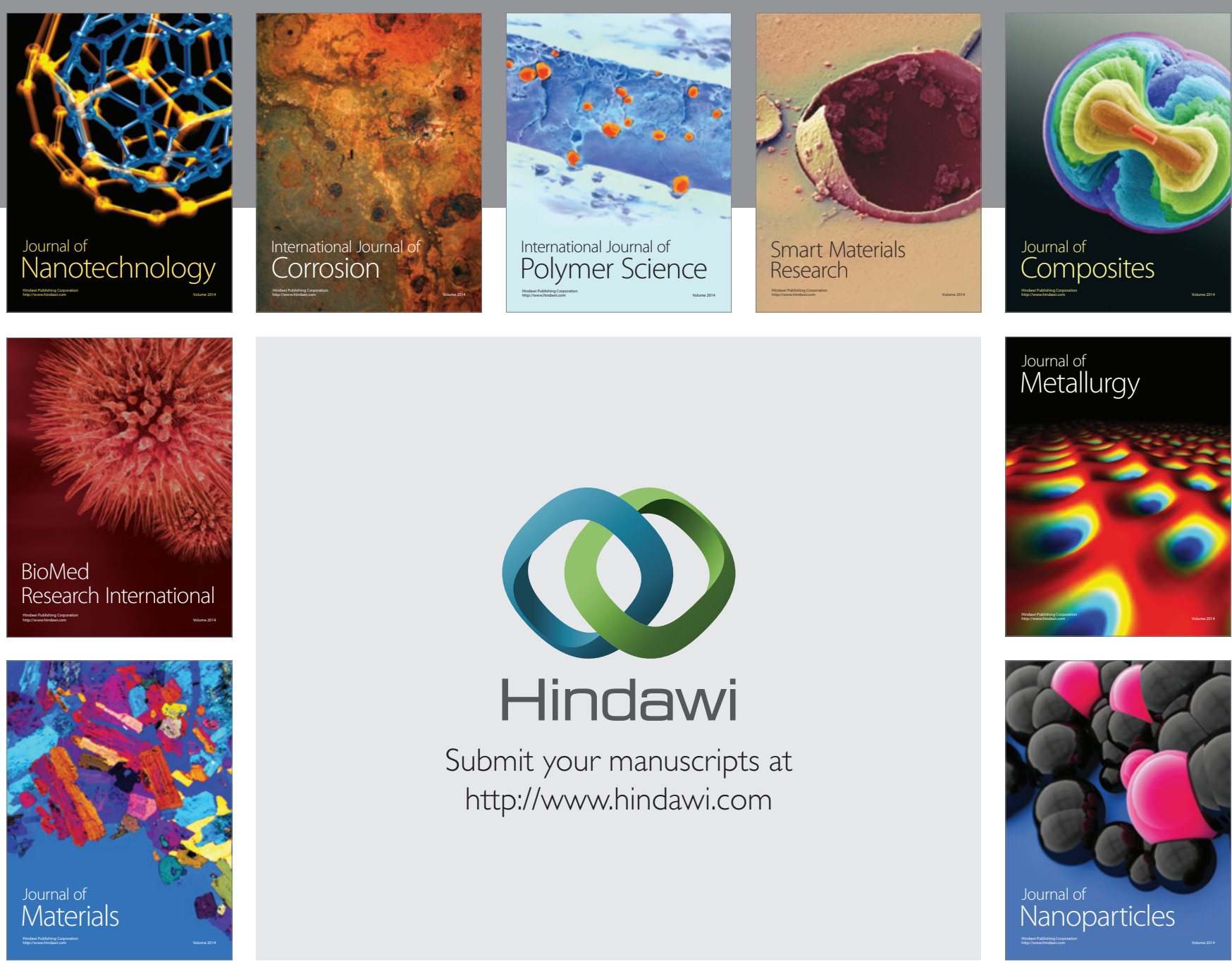

\section{Hindawi}

Submit your manuscripts at

http://www.hindawi.com

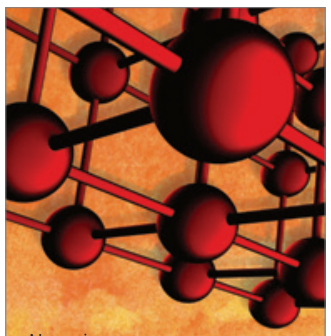

Materials Science and Engineering
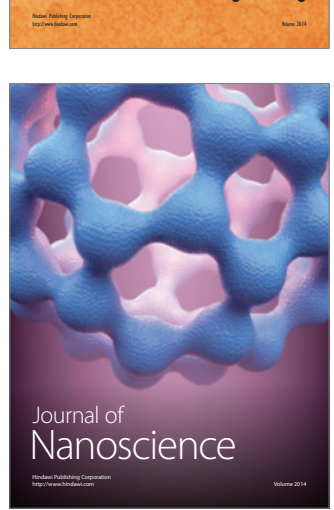
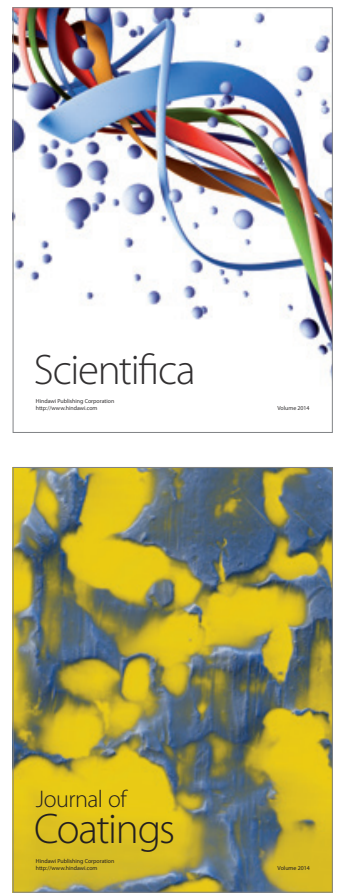
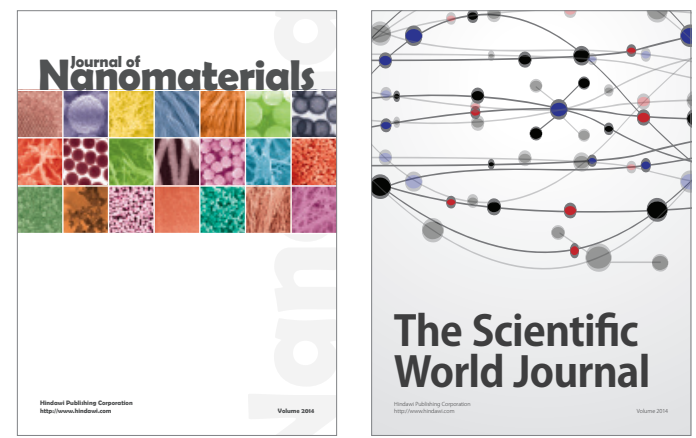

The Scientific World Journal
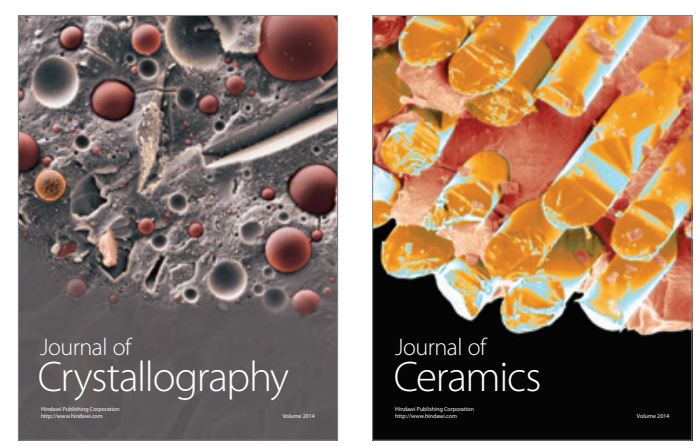
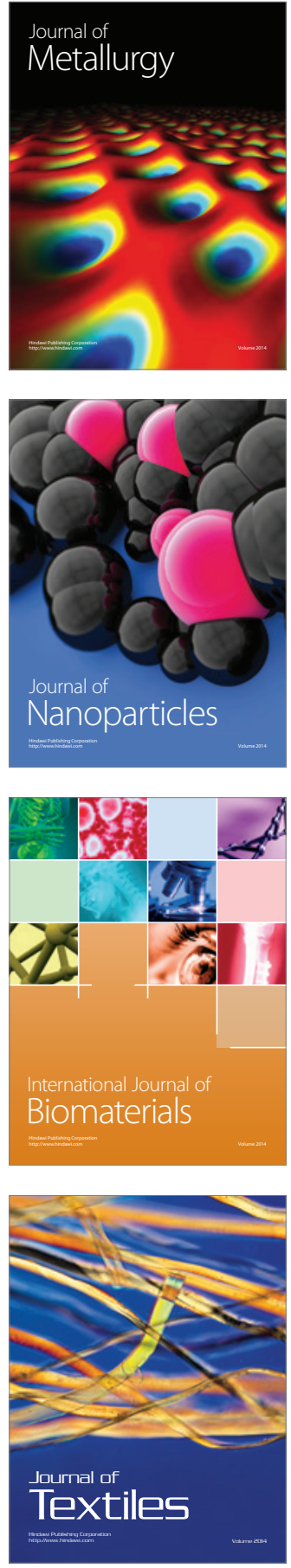